\title{
Geophysical Investigation For Groundwater Using Electrical Resistivity Method - A Case Study Of Annunciation Grammar School, Ikere Lga, Ekiti State, South-Western Nigeria
}

\author{
Lateef T.A. \\ Department of Physics, University of Ado-Ekiti, Ekiti State.
}

\begin{abstract}
Geophysical survey involving electrical resistivity methods has been carried out at Annunciation grammar school, Ikere- Ekiti, southwestern Nigeria with the view to delineate the geo-electric characteristics of the basement complex and evaluate its groundwater potential in the area. A total of 5 vertical electrical sounding stations were established within the site along 5 traverses.

The schlumberger configuration was used for the data acquisition. The half-currents electrode $(A B / 2)$ used range from 1 to $100 \mathrm{~m}$. The quantitative interpretation of the VES curves involved the use of partial curve matching and the 1-D computer iteration technique. The depth sounding interpretation results were used to generate geo-electric sections from which the aquifer was delineated.

The geo-electric section drawn from the results of the interpretation reveal five subsurface layer which comprises of the topsoil, lateritic sand, partially weathered, weathered and fractured basement. The weathered and fractured layers constituted the aquiferous zone in all the stations.

Hence, from this project work it is recommended that boreholes can be sited in high conductivity zones in VES 1,2,3 and 4 as they contain probable aquifers. The depth of any borehole should be located between $15 \mathrm{~m}$ and $30 \mathrm{~m}$ to take advantage of the basement fractures
\end{abstract}

Keywords: Geo-electric, overburden, lateritic, resistivity, foundation

\section{Introduction}

The science of Geophysics applies the principles of physics to the study of the earth. Geophysical Investigation of the earth involves taking measurement at or near the earth's surface that are influence by the internal distribution of physical properties.

Most human generally requires about 2.5 litres of water everyday which justify the average amount of water used domestically each day by every person is around 190litres.Generally, industries require approximately one third of the public water supply, with the remainder being used in the home. Thus the total per capital day use is around 300 litres per day.

Normally, the easiest and most convenient way to meet the public demand for water are Rivers and lakes, less than 0.01 percent of the world's total water and less than two percent of the world's fresh water. It is distributed spatially and temporarily in an irregular manner while the sources available has often been polluted. Groundwater, on the other hand accounts for about ninety-eight percent of the world's reasonably constant supply, which is not likely to dry up under natural conditions in crust to the surface sources.

The groundwater on the contrary is significantly protected from surface pollutants as the earth media (composed of different subsurface layer) act as a natural filter to infiltrated water. It very rarely cheaper to be developed. Interestingly, the volume of groundwater is considerable. Olorunfemi et al,(1999) puts its volume at 2000 times that of the volume of water in all world's rivers at any given time. Groundwater development therefore constitutes a viable option or supplement to the expensive earth/concrete dam system of surface water supply, where potential groundwater is good.

If a groundwater is to be exploited, it is essential that the entire project be conducted in most efficient and cost-effective way possible. Rushing into groundwater development program will probably result in the incorrect location of points, inefficient design of the abstraction works. The feasibility of using the geo-electric method to determine resistivity, depth and thickness of the model earth layers, estimation of the number of smooth and equivalence layers corresponding to the number of model earth layers (stratigraphic correlation) (Kunetz, 1966). The evaluation development and management of an aquifer for water supply should proceed in stages. The aim of this study is to map possible fractured assisted aquiver system in study area and to achieve these objectives which are; determination of the geo-electric parameters and overburden thickness in the area from the VES data, and construct earth model revealing geo-electric sequence/subsurface lithology in the area. 


\section{Site Description}

The survey site is Annunciation grammar school in Ikere-Ekiti. The area is situated on Latitude $8^{0} 12^{1} \mathrm{~N}$ to $8^{0} 14^{1} \mathrm{~N}$ and longitude $7^{0} 14^{1} \mathrm{E}$ to $7^{0} 16^{1} \mathrm{E}$. The site consists of a three unit of two-storey building, which housed the administrative block, the junior secondary student and senior secondary student. The school is educational in nature; it runs day and boarding system. The compound is well fenced and the topography is highly undulating and rugged.

The area is characterized by short dry season and long wet season and has high rainfall of about $160 \mathrm{~mm}$ and peak rainfall between August and September. High temperature ranging between with relatively high humidity during the wet season and low humidity during the dry season (Rahman, 1976).

The area is situated in the rain forest type of vegetation and is characterized by dense evergreen forest. Thick vegetation, farming and forest depletion and other main activities have affected the natural vegetation. The basement complex rocks are crystalline rocks of low porosity and permeability. In this geologic environment groundwater accumulation depends on (i) degree of weathering and thickness of the overburden, (ii) degree and nature of fracturing of the rocks, (iii)the presence and absence of clays above the weathered zone and its effect on rate of infiltration of water into the aquifer, (iv) the hydrological continuity (permeability) of the weathered zone.

Source of recharge in the area include stream and precipitation, cracks, fractures bedrock depression and weathered basement are the geologic subsurface structure in basement terrain that can favor groundwater accumulation. Porosity, permeability and transmissivity are the parameters of an aquifer. A good aquifer must have high porosity, high permeability and transmissivity.

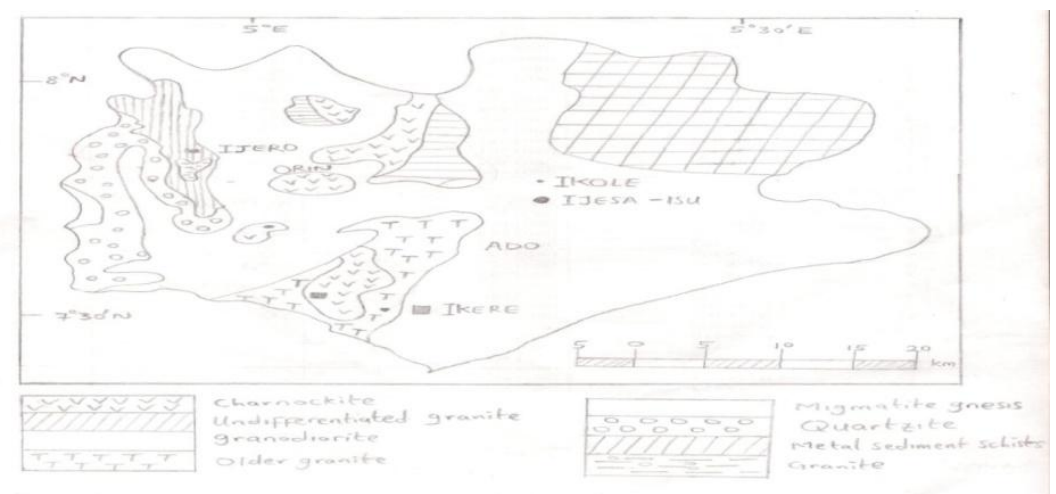

Figure: 1. Geological map of Ekiti State

Olorunfemi et al, (1999) studied the geoelectric parameters and aquifer characteristics of some parts of western Nigeria. They concluded that the clayey sand and sand area and the fractured basement constitutes the aquifer zones. Thus, they concluded that the highest transverse resistance (T) corresponds to the zone with the highest borehole yield and determined the strike of foliation of concealed solid rock (in which the predominant structural feature is the foliation or where the fracture /joint direction are generally in line with strike of foliation). The electrical resistivity method has been used successfully in location site for borehole development in south western basement of Nigeria. It is unique because of its ability to detect increases in pore water conductivity (Abdul Nasir et al, 2000, Adepelumi et al 2008). The studies reviewed show that geophysical methods are applicable to hydrological investigation and the delineation of geologic structures and materials.

$\mathrm{T}$ he objective of this study is to map possible fractured assisted aquifer system in study area and determine the geoelectric parameters and overburden thickness in the area from the VES data.

\section{Materials And Method}

The electrical resistivity survey involves electrical sounding using schlumberger configuration with ABEM WADI (SAS 300B) Terameter. The potential electrodes remain fixed and the current electrodes are expanded simultaneously about the center of the spread. The distance between the electrodes gets too large, it then mandatory to increase the distance between the potential electrodes to have a measurable potential difference.

The schumberger array used, with maximum current electrode separation of $100 \mathrm{~m}-150 \mathrm{~m}$ electrodes are normally arranged along a straight line, with the potential electrode placed in between the current electrodes. This configuration is mostly used as it would provide subsurface information considering the depth of penetration which ranges between $1 / 3$ and $1 / 4$ of the total current electrode separation (David and Ofrey, 1989; Osemeikhian and Asokhia, 1994; Mallam and Ajayi,2000).The resistivity sounding curves were interpreted quantitatively; this is done by partial curve matching technique and computer iteration of the interpreted resistivity curves. Partial curve matching method involves a segment matching of the sounding curves with 
theoretical schlumberger layer. The interpretation was done by matching the VES curves segment by segment, starting from small electrode spacing gradually to larger electrode spacing. The process involves taking the apparent resistivity data in ohm-meter obtained from the study area and plotting it against the electrode spacing in meters on a transparent double logarithmic paper or is superimposed on a $\log ^{2}$ by 3 cycle graph to obtain a curve of best fit, with the axis of the two graphs parallel to each other. The transparent double logarithmic paper with its final curve match is then placed back on the $\log$-log graph, and the value of the apparent resistivity for the first layer $\ell$, and its corresponding layer thickness in meter $\mathrm{h}$ are obtained. Also obtained from the bi-log graph of the subsequent points of curve matching i.e from the two layers apparent resistivity curve are reflected apparent resistivity's $\ell$ values with their corresponding reflected layer thickness $h_{r}$ and the depth ratio $\frac{D n}{D r_{n}}$ is obtained from auxiliary curve. Hence, the following equations are used for subsequent calculations of the respective layer resistivity's and their thickness, i.e. to calculate the second layer resistivity $\ell_{2}$ and thickness $h_{2}$. Computer assisted interpretation is usually based on the algorithm which employs digital linear filters for the fast computation of resistivity function for a given set of layers parameters. This technique involves seeing a solution to the inverse problem in the kernel functions which is useful in interpreting apparent resistivity measurement in the terms of lithological variation with depth. The function assumes the earth to be resistivity functions it is independent of electrode configuration. A computer programs known as WIN RESIST was used.

\section{Results And Discussion}

The vertical electrical sounding (VES) data are presented as depth sounding curve, which are obtained by plotting apparent resistivity values against electrode spacing on a log-log or bi-log graph paper. The depth sounding curves are classified based on layer resistivity combinations. The curve types obtained in the study area where five VES sounding was carried out include the QH, KH, and KHK types. The QH- type curve: The curve is predominant in the study area constituting $45 \%$ of the total number of the VES curve. It was obtained at two points VES 1 and 3. The $\mathrm{H}$-curve has an intermediate layer of low resistivity value that is recognized as the aquifer unit at these VES location. The extent to which the rocks have been weathered or fractured determines the amount of water to be found and these in turn govern the electrical resistivity values (Nwankwo et al, 2004). The weathered layer constitutes the hydro geologically significant layer because of its water bearing capacity and characterized by high porosity, relatively high permeability and high specific yield. The $\mathrm{KH}-$ type curve: The KH type curve is a five layer model of the subsurface and was obtained at VES 2 and 4. The first layer is the topsoil, followed by a sandy formation and the weathered layer in that order. The weathered layer in these sequences is very favorable for underground water abstraction. The KHK- type curve: Another type KHK was obtained as minority being obtained only at VES 5 of the study area. The curve type is characterized by a steady decrease in resistivity value. This curve type does not guarantee the possibility of abstracting water in substantial quantity from the VES point were the weathered layer is a clayey formation i.e. an aquitard.
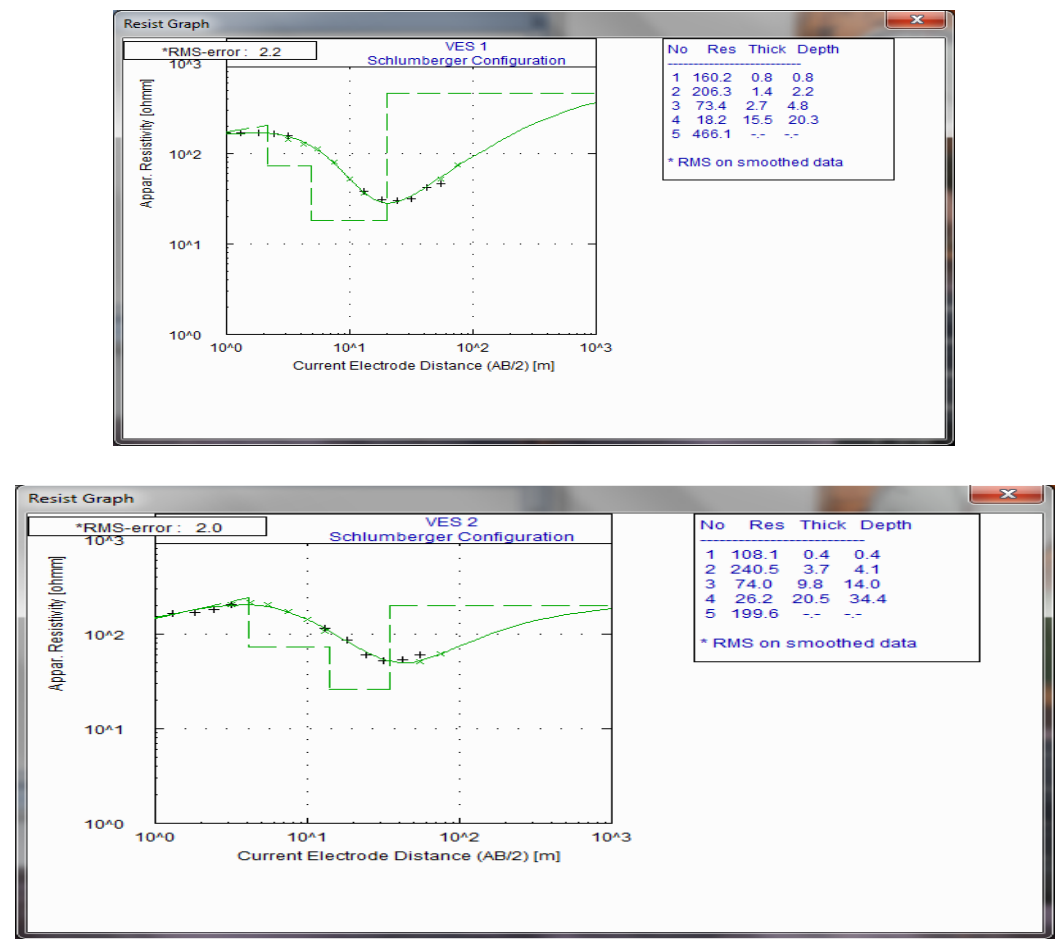


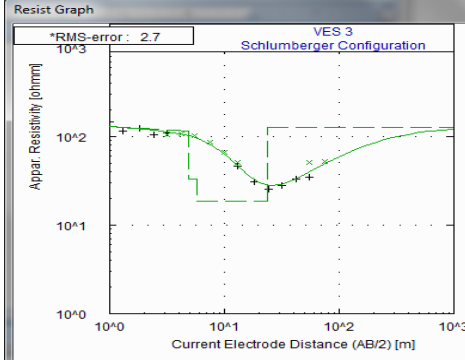

\begin{tabular}{|llll} 
No & Res & ThICK & De \\
\hline 1 & 136.3 & 0.6 & 0.6
\end{tabular}

$\begin{array}{cccc}1 & 114.1 & 4.2 & 4.8 \\ 3 & 33.1 & 0.9 & 5.8 \\ 4 & 18.5 & 17.9 & 23 \\ 4 & 18.9\end{array}$

* RMS on smoothed data
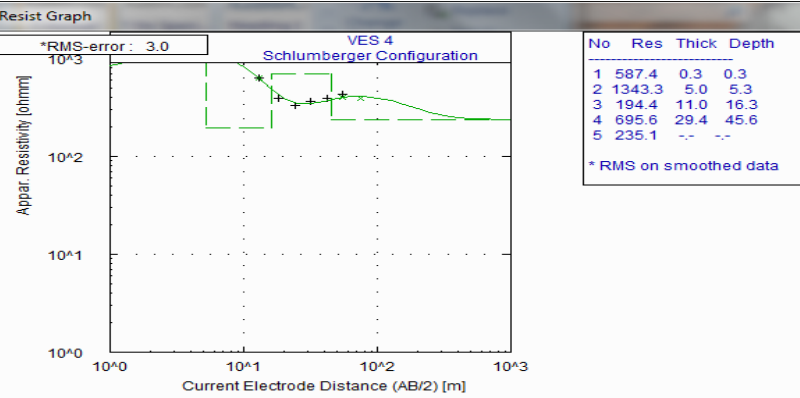

RMS on smoothed data
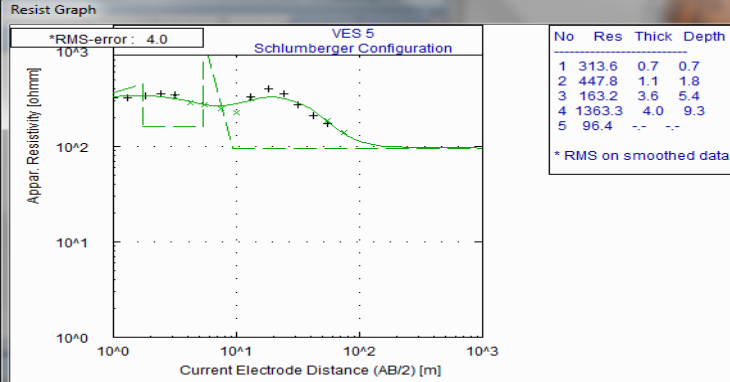

Table of VES data and the delineated lithologies in the study area.

\begin{tabular}{|c|c|c|c|c|c|c|}
\hline $\begin{array}{l}\text { VES } \\
\text { NO }\end{array}$ & $\begin{array}{l}\text { CURVE } \\
\text { TYPE }\end{array}$ & $\begin{array}{l}\text { LAYER } \\
\text { NO }\end{array}$ & $\begin{array}{l}\text { RESISTIVITY } \\
(\Omega \mathrm{m})\end{array}$ & $\begin{array}{l}\text { THICKNESS } \\
\text { (m) }\end{array}$ & $\begin{array}{l}\text { DEPTH } \\
(\mathrm{m})\end{array}$ & LITHOLOGY \\
\hline \multirow[t]{5}{*}{1} & $\mathrm{QH}$ & 1 & 160 & 0.8 & 0.8 & Topsoil \\
\hline & & 2 & 206 & 1.4 & 2.2 & Sandy clay \\
\hline & & 3 & 73 & 2.7 & 4.8 & Clay \\
\hline & & 4 & 18 & 15.5 & 20.3 & Weathered layer \\
\hline & & 5 & 466 & & & $\begin{array}{l}\text { Fractured } \\
\text { basement }\end{array}$ \\
\hline \multirow[t]{5}{*}{2} & $\mathrm{KH}$ & 1 & 108 & 0.4 & 0.4 & Topsoil \\
\hline & & 2 & 241 & 3.7 & 4.1 & Lateritic sand \\
\hline & & 3 & 74 & 9.8 & 14 & $\begin{array}{l}\text { Partially } \\
\text { weathered layer }\end{array}$ \\
\hline & & 4 & 26 & 20.5 & 34.4 & $\begin{array}{l}\text { Weathered/fractur } \\
\text { ed basement }\end{array}$ \\
\hline & & 5 & 200 & & & $\begin{array}{l}\text { Fractured } \\
\text { basement }\end{array}$ \\
\hline \multirow[t]{5}{*}{3} & $\mathrm{QH}$ & 1 & 136 & 0.6 & 0.6 & Clayey/sandy \\
\hline & & 2 & 114 & 4.2 & 4.8 & Lateritic sand \\
\hline & & 3 & 33 & 0.9 & 5.8 & $\begin{array}{l}\text { Partially } \\
\text { weathered layer }\end{array}$ \\
\hline & & 4 & 19 & 17.9 & 23.6 & Weathered layer \\
\hline & & 5 & 127 & & & Fractured \\
\hline
\end{tabular}




\begin{tabular}{|l|l|l|l|l|l|l|}
\hline & & & & & & basement \\
\hline 4 & KH & 1 & 564 & 0.3 & 0.3 & Topsoil(sand) \\
\hline & & 2 & 1383 & 4.4 & 4.7 & Lateritic sand \\
\hline & & 3 & 278 & 25.9 & 30.6 & Weathered layer \\
\hline & & 4 & 763 & 92 & 122.5 & $\begin{array}{l}\text { Weathered/fractur } \\
\text { ed basement }\end{array}$ \\
\hline 5 & KHK & 1 & 314 & 0.7 & 0.7 & $\begin{array}{l}\text { Fractured } \\
\text { basement }\end{array}$ \\
\hline & & 2 & 448 & 1.1 & 1.8 & Coarse grained \\
sand
\end{tabular}

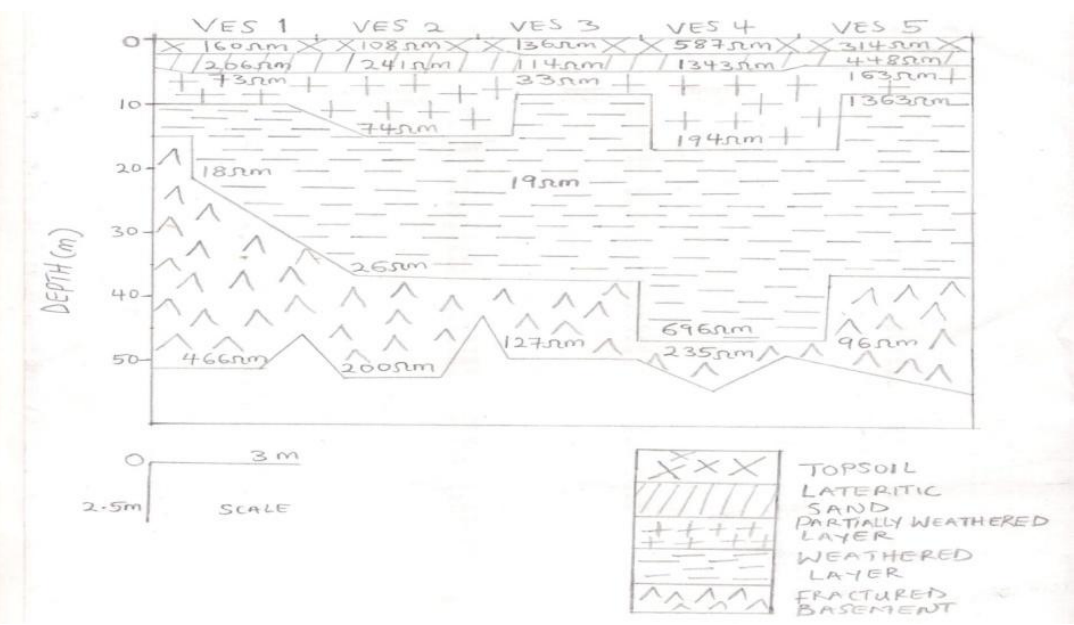

Figure 3: Geo-electric section through all VES stations in the study area.

\section{Geoelectric Section}

The geo-electric section across the stations generally shows the different subsurface layers and the depth at which they are encountered during the course of investigation in relation to layer resistivity's. The geoelectric section was drawn across VES 1,2,3,4 and 5, in the direction that approximately N-E. The section has five layers at the VES points.

The first layer is the topsoil which is composed of sandy clay, sandy, coarse grained sand and clayey/sandy formation. This layer resistivity values from $108 \Omega m$ to $587 \Omega m$ and a thickness between $0.3 m$ and $0.8 \mathrm{~m}$. This layer serves as a site for evapotranspiration and pipeline lying. It is generally unreliable for groundwater accumulation in all the VES stations. The second layer is the lateritic sand, it comprises of wet, moist, dry and saturated laterite. The resistivity ranges from $114 \Omega m$ to $1343 \Omega m$ and the thickness ranges from $1.8 \mathrm{~m}$ and $5.3 \mathrm{~m}$, having a poor hydrogeological characteristics. This layer is sufficient and recommend for site foundation and road construction. The third layer is partially weathered layer and has resistivity of $33 \Omega \mathrm{m}$ and $74 \Omega \mathrm{m}$ and a thickness of $0.9 \mathrm{~m}$ and $9.8 \mathrm{~m}$, these layer are found in VES 2 and 3 . The VES station 1,4 and 5 falls into moist laterite and weathered formation. This layer is partially convenient for ground water accumulation and hence the aquifer can not yield water in sufficient quantity and economical use.

The fourth layer is the weathered layer and the resistivity value ranges from $18 \Omega \mathrm{m}$ to $696 \Omega \mathrm{m}$ and the thickness ranging from $15 \mathrm{~m}$ and $29 \mathrm{~m}$. This layer thickness and aquifer enhance the accumulation for efficient groundwater potential. It is very favorable and productive in borehole construction. The weathered/fracture zone gives rise for the convenient flow of water from the aquifer to the earth surface.

The fifth layer is the fractured basement and this layer has resistivity values from $96 \Omega \mathrm{m}$ to $446 \Omega \mathrm{m}$ and the thickness ranges to infinity. This section indicates high resistivity value and is good for groundwater accumulation. 


\section{Conclusion}

Vertical electrical sounding technique of the electrical resistivity method has proven to be successful and highly effective in the identification and delineation of subsurface structures that are favorable for groundwater accumulation in a crystalline basement complex area. The electrical resistivity survey method used in this project entails locating a favorable borehole at Annunciation Grammar School, in Ikere- Ekiti revealed five subsurface geo-electrical layers. These consist of the topsoil, weathered layer and the fractured basement. However the fractured basement is found in all the segments of the study area.

\section{References}

[1] Olorunfemi, M. O., Ojo, J. S. and Akintunde, O.M. (1999); "Hydro-geophysical evaluation of the groundwater potential of the Akure metropolis, Southwestern Nigeria”. Journal of Mining and Geology Vol. 35(2) 1999, pp. 207 - 228

[2] Kunetz, G. (1966). Principles of direct current resistivity prospecting, Borntraeger, Berlin.

[3] Rahman, M.A. (1976): "Review of the Basement Geology of South Western Nigeria". In geology of Nigeria (Kogbe, C.A.C.Ed.). Elizabethan Pub!. co.,Nigeria pp.41-58.

[4] Abdul Nasir, S. S., Loke, M. H., Lee, C. Y., and Nawawi, M. N. M., 2000; Salt water intrusion mapping by geo-electrical imaging surveys. Geophys. Prospect, 48: $647-661$.

[5] Adepelumi, A. A., Ako,B. D., Ajayi, T. R., Afolabi, O. and Omotoso, E. J.2008; Delineation of salt water intrusion into fresher water Aquifer of Lekki- peninsula, Lagos,Nigeria. Environ. Geol. 56: 927 - 933.

[6] David, L.M., and Ofrey, O. (1989): “An indirect method of estimating ground water level in basement complex regolith". Water resources, Vol. 1,No. 2, pp. $34-41$.

[7] Osemeikhian,J. E. A. and Asokhia, M. B. (1994); Applied Geophysics for engineers and geologists. 1 Ed. Samtos services Ltd., Lagos.

[8] Mallam, A. and Ajayi, C. O. (2000); Resistivity method for groundwater investigation in sedimentary area. Nig. J. of Physics, 12, 34 -38 .

[9] Nwankwo, L. I., Olasehinde, P. I. and Babatunde, E. B. (2004); The use of electrical resistivity pseudosection in elucidation the geology of an east-west profile in the basement complex terrain of Ilorin, West-Central, Nigeria. Nig. J.of Pure and Appl. Sci., 19, $167-1682$. 